\title{
Exercise tolerance in children with cystic fibrosis undergoing lung transplantation assessment
}

\author{
P. Aurora*, S.A. Prasad*, I.M. Balfour-Lynn", G. Slade*, B. Whitehead*, R. Dinwiddie*
}

Exercise tolerance in children with cystic fibrosis undergoing lung transplantation assessment. P. Aurora, S.A. Prasad, I.M. Balfour-Lynn, G. Slade, B. Whitehead, R. Dinwiddie. (C) ERS Journals Ltd 2001.

ABSTRACT: The aim of this study was to compare the 6-min walk test against the recently developed 3-min step test, as measures of exercise tolerance in children with moderate to severe cystic fibrosis (CF) lung disease referred for lung transplantation assessment.

Twenty-eight children with CF (16 girls, 12 boys), with a mean age of 13.7 yrs (range 7.2-17.8 yrs) and mean forced expiratory volume in one second of $34 \%$ predicted (range $17 \%-67 \%$ ) were recruited. All subjects performed both the 6-min walk and 3-min steptests. Outcome measures were maximum rise in heart rate (HR), and maximum fall in arterial oxygen saturation $\left(S_{\mathrm{a}}, \mathrm{O}_{2}\right)$.

There was no significant difference in resting $\mathrm{HR}$ or $\mathrm{S}_{\mathrm{a}}, \mathrm{O}_{2}$ prior to starting the two tests. Both step and walk tests produced significant rises in median HR (from 114-149 $\mathrm{min}^{-1}, \mathrm{p}<0.0005$, and 119-138 $\mathrm{min}^{-1}, \mathbf{p}<0.0005$, respectively) and significant falls in $\mathrm{Sa}_{\mathrm{a}}, \mathrm{O}_{2}$ (both from $94-92 \%, \mathrm{p}<0.0005$ ). The step test produced a significantly greater percentage rise in $\mathrm{HR}(30 \%$ versus $18 \%, p<0.0005)$ and a significantly greater percentage fall in $\mathrm{Sa}_{\mathrm{a}} \mathrm{O}_{2}(4 \%$ versus $2 \%, \mathrm{p}=0.002)$. Bland-Altman analysis gave wide $95 \%$ limits of agreement $\left(10.7-29.3 \%\right.$ for rise in $\mathrm{HR},-\mathbf{2 . 1 - 4 . 6 \%}$ for fall in $\left.\mathrm{S}_{\mathrm{a}}, \mathrm{O}_{2}\right)$. The step test was well tolerated.

The 3-min step test produced a greater fall in $S_{\mathrm{a}}, \mathrm{O}_{2}$ and a greater rise in HR than the 6-min walk test in children with moderate to severe $\mathrm{CF}$ lung disease. It may be of value when assessing a child's suitability for lung transplantation.

Eur Respir J 2001; 18: 293-297.
*Cardiorespiratory and Critical Care Directorate, Great Ormond Street Hospital for Children, London, UK and ${ }^{\#}$ Dept of Paediatric Respiratory Medicine, Royal Brompton Hospital, London, UK.

Correspondence: P. Aurora, Portex Anaesthesia, Intensive Therapy and Respiratory Medicine Unit, Institute of Child Health, 30 Guilford Street, London WC1N 1EH, UK.

Fax: 442078298634

\section{Keywords: Children}

cystic fibrosis

exercise

lung transplantation

Received: June 292000

Accepted after revision March 192001
Measurement of exercise tolerance is considered an essential component of the lung transplantation assessment procedure, since it may predict life expectancy and provide valuable information regarding the patient's quality of life. A variety of tests have been considered for measurement of exercise tolerance in children, the most commonly used being the selfpaced walking test. In this test, the subject is asked to walk as far as possible during a set time $(2,6$ or $12 \mathrm{~min}$ ) and the distance covered, the increase in heart rate $(\mathrm{HR})$, and the change in arterial oxygen saturation $\left(S \mathrm{a}, \mathrm{O}_{2}\right)$ are recorded [1-3].

Although distance covered during a walk test has been shown to correlate with survival in adults with lung disease [4], data from children with cystic fibrosis (CF) suggest this measure may be a less useful prognostic indicator [5], possibly because results from walk tests can vary with encouragement and patient motivation. A 3-min step test has been developed, which might rely less on patient motivation than a self-paced walk test. During a walk test the subjects are asked to cover as much distance as possible in the allotted time but are allowed to choose their own pace of walking and rest during the test. Poorly-motivated subjects may walk more slowly than well-motivated subjects. During a step test the intensity of exercise is predetermined, so a poorly motivated subject may stop the test early (though this is rare in practice), but may not slow down.

A previous study demonstrated that, in a diverse population of children with $\mathrm{CF}$, the step test produces a greater increase in $\mathrm{HR}$ and greater increase in breathlessness (measured by a modified Borg score) than the 6-min walk. However, the two tests produced a similar fall in $\mathrm{Sa}_{\mathrm{a}} \mathrm{O}_{2}$ [6]. In the current study the 3-min step test was compared with a 6-min walk test in a population of children with moderate to severe $\mathrm{CF}$ lung disease referred for lung transplantation assessment.

\section{Materials and methods}

\section{Study subjects}

All children with $\mathrm{CF}$ attending Great Ormond Street Hospital for Children, London, UK for lung transplantation assessment between January 1998 and November 1998 were recruited to this study. A total of 28 children with moderate-to-severe CF lung disease were enrolled. All children had been referred from $\mathrm{CF}$ centres in the UK or Republic of Ireland. There were 
Table 1. - Change in heart rate $(\mathrm{HR})$ and oxygen saturation $\left(\mathrm{Sa}, \mathrm{O}_{2}\right)$ during the two tests

\begin{tabular}{lcccccc}
\hline & Pretest $\mathrm{HR} \cdot \mathrm{min}^{-1}$ & Maximum HR $\cdot \mathrm{min}^{-1}$ & $\mathrm{p}$-value & Pretest $\mathrm{Sa}_{\mathrm{a}, \mathrm{O}_{2}} \%$ & Minimum $S_{\mathrm{a}, \mathrm{O}_{2} \%} \%$ & $\mathrm{p}$-value \\
\hline 6-min walk test & $119(106-128)$ & $138(130-150)$ & $<0.005$ & $94(93-95)$ & $92(90-94)$ & $<0.005$ \\
3-min step test & $114(104-125)$ & $149(139-156)$ & $<0.005$ & $94(92-96)$ & $92(88-94)$ & $<0.005$ \\
p-value & NS & NS & & NS & NS & \\
\hline
\end{tabular}

Data are presented as medians (interquartile ranges).

16 girls and 12 boys with a mean age of 13.7 yrs (range 7.2-17.8 yrs), and a mean forced expiratory volume in one second (FEV1) of $34 \%$ predicted for height, age and sex [7] (range 17-67\%).

\section{Study design}

All subjects performed both the 6-min walk test and the 3-min step test. Order of testing was alternated. Baseline $\mathrm{Sa}_{\mathrm{a}} \mathrm{O}_{2}$ and $\mathrm{HR}$ were recorded, then subjects were trained in performance of both tests, practised, and rested. The second test was performed $30 \mathrm{~min}$ after $\mathrm{HR}$ and $\mathrm{Sa}_{\mathrm{a}} \mathrm{O}_{2}$ had returned to baseline levels. $\mathrm{HR}$ and $\mathrm{S}_{\mathrm{a}}, \mathrm{O}_{2}$ were measured continuously during exercise by pulse oximetry, and outcome measures were maximum fall in $\mathrm{Sa}_{\mathrm{a}} \mathrm{O}_{2}$ and maximum rise in $\mathrm{HR}$ during exercise.

\section{Methods}

The step test required subjects to step up and down a $15 \mathrm{~cm}$ step at a rate of $30 \mathrm{steps} \cdot \mathrm{min}^{-1}$ for $3 \mathrm{~min}$. The stepping rate was controlled by a metronome. $\mathrm{Sa}, \mathrm{O}_{2}$ and HR were measured by pulse oximetry (Ohmeda Biox pulse oximeter, Boulder CO, USA) with a flexiprobe attached to the patients finger and its lead strapped to the patients arm. Subjects stopped if their $\mathrm{Sa}_{\mathrm{a}} \mathrm{O}_{2}$ fell to $<75 \%$ or if they felt over-tired. Patients were shown how to change the leading leg to reduce localized muscle fatigue and standardized encouragement was given. The 6-min walk test required subjects to walk up and down a $17 \mathrm{~m}$ corridor for $6 \mathrm{~min}$ accompanied by the investigator. The test was selfpaced with subjects asked to cover the maximum possible distance in the allotted time. If subjects wished to rest they could do so but the clock continued to run. $\mathrm{Sa}_{\mathrm{a}, \mathrm{O}_{2}}$ and $\mathrm{HR}$ were measured as for the step test. The test was discontinued if the $\mathrm{Sa}_{\mathrm{a}} \mathrm{O}_{2}$ fell to $<75 \%$. Total distance walked was also recorded.

\section{Data analysis}

Wilcoxon signed ranks tests were used to compare outcome measures before and after exercise and to compare changes in outcome measures for the two tests. Bland-Altman plots [8] were also used to compare changes in the outcome measures for the two tests. In this analysis, the difference between the percentage change in $\mathrm{HR}$ (or $\mathrm{Sa}_{\mathrm{a}} \mathrm{O}_{2}$ ) obtained by the two tests is plotted against their mean value. The group mean difference can also be calculated, as can the limits of agreement (defined as 2sDs from the group mean difference).

\section{Results}

Of the 28 children tested, six had an FEV $1>40 \%$, and 22 had an $\mathrm{FEV} 1<40 \%$. There was no significant difference between the resting $\mathrm{Sa}_{\mathrm{a}} \mathrm{O}_{2}$ or resting $\mathrm{HR}$ prior to starting the two tests. Both tests produced a significant fall in $\mathrm{Sa}_{\mathrm{a}} \mathrm{O}_{2}$ and a significant rise in $\mathrm{HR}$ (table 1, fig. 1 and 2). The step test produced a significantly greater percentage rise in HR (median of $30 \%$ versus $18 \%$ ), and a significantly greater percentage fall in $\mathrm{Sa}_{\mathrm{a}} \mathrm{O}_{2}$ (median of $4 \%$ versus $2 \%$ ), than the

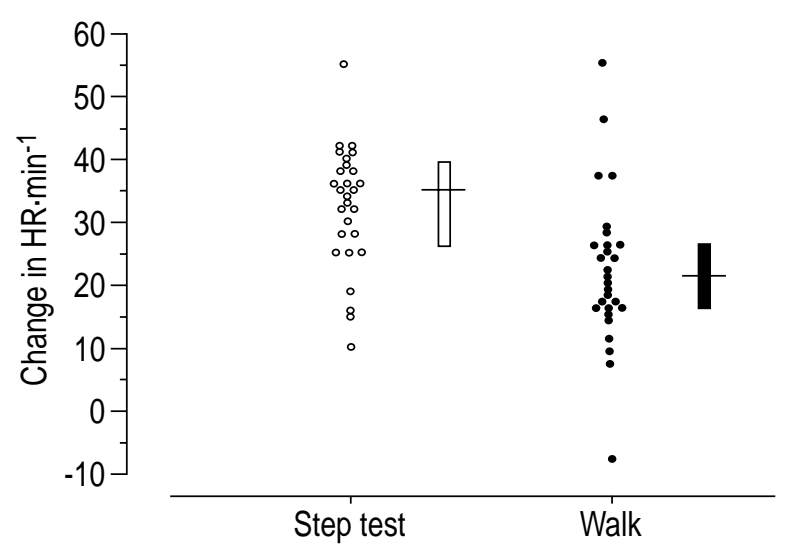

Fig. 1.-Absolute changes in heart rate (HR) during step test $(\bigcirc)$ and walk test $(\bullet)$. Also shown are medians (line) and interquartile ranges (bars).

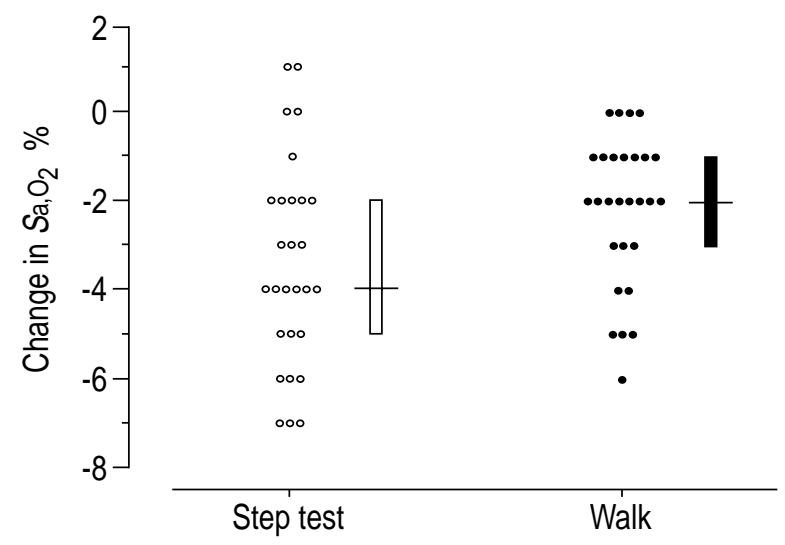

Fig. 2.-Absolute changes in arterial oxygen saturation $\left(S_{\mathrm{a}}, \mathrm{O}_{2}\right)$ during step test $(\bigcirc)$ and walk test $(\bullet)$. Also shown are medians (line) and interquartile ranges (bars). 
Table 2. - Percentage fall in heart rate $(\mathrm{HR})$ and percentage fall in arterial oxygen saturation $\left(\mathrm{Sa}, \mathrm{O}_{2}\right)$ for the two exercise tests.

\begin{tabular}{|c|c|c|c|}
\hline & 6-min walk & 3-min step & p-value \\
\hline & $18(13-26)$ & $30(20-36)$ & $<0.0005$ \\
\hline Percentage fall in $\mathrm{Sa}_{\mathrm{a}} \mathrm{O}_{2}$ & $2(1-4)$ & $4(2-6)$ & 0.002 \\
\hline
\end{tabular}

Data are presented as medians (interquartile ranges).

walk test (table 2). When the study population was divided according to order of testing, no significant difference was found between the two groups for FEV1, median desaturation for either test, or median rise in HR for either test.

Bland-Altman analysis of the two tests gave wide 95\% limits of agreement for rise in HR (-10.7-29.3\%). Twenty-four of the 28 children had a greater increase in HR with the step test than with the walk test (fig. 3). Bland-Altman analysis for fall in $\mathrm{Sa}_{\mathrm{a}} \mathrm{O}_{2}$ also showed wide $95 \%$ limits of agreement (-2.1-4.6\%), though examination of the plot shows that the difference between the two tests was most marked in those patients who showed the greatest desaturation on exercise (fig. 4). Four subjects had little desaturation on exercise, whereas of the 24 subjects who showed a mean desaturation of $\geq 1 \%$, the majority had greater desaturation with the step test than the walk test, and none had a greater desaturation with the walk test than with the step test.

\section{Discussion}

In the present study, the recently developed 3-min step test was compared with the well-established 6-min walk test in a population of children with moderate to severe CF lung disease. Both tests produced a significant rise in $\mathrm{HR}$, and a significant fall in $\mathrm{Sa}_{\mathrm{a}} \mathrm{O}_{2}$. The step test produced a significantly greater rise in $\mathrm{HR}$ and a significantly greater fall in $\mathrm{Sa}_{\mathrm{a}} \mathrm{O}_{2}$ than the walk test, with the greatest difference between the two tests noted in those patients with the

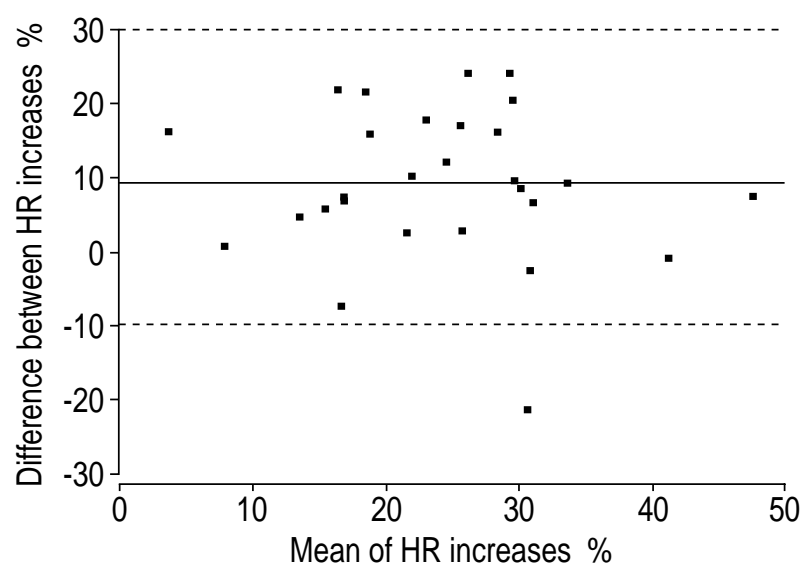

Fig. 3.-Bland-Altman plot of percentage change in heart rate (HR) between 6-min walk test and 3-min step test versus mean of the two tests. Unbroken and broken lines represent mean and mean $\pm \mathrm{SD}$, respectively.

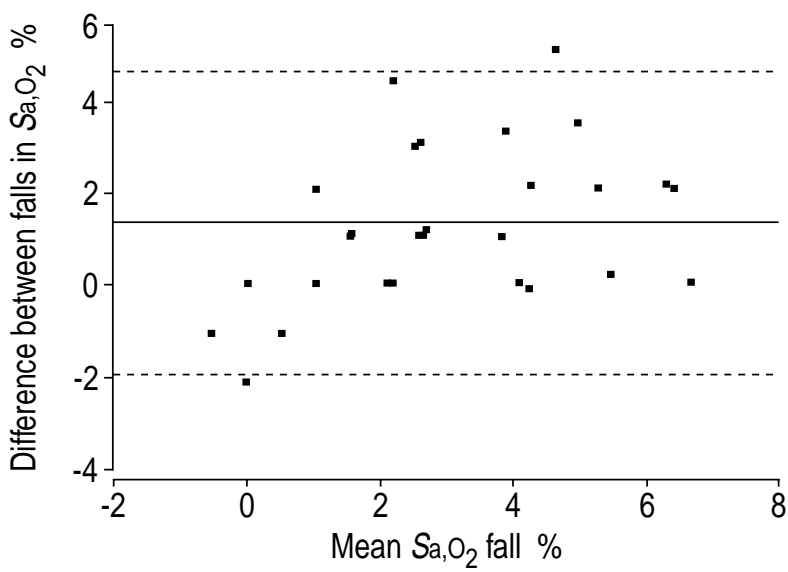

Fig. 4.-Bland-Altman plot of percentage change in arterial oxygen saturation $\left(\mathrm{S}_{\mathrm{a}}, \mathrm{O}_{2}\right)$ between 6 -min walk test and 3-min step test versus mean of the two tests. Unbroken and broken lines represent mean and mean $\pm \mathrm{SD}$, respectively.

greatest propensity to desaturate on exercise. This last finding was not observed in a previous study of $\mathrm{CF}$ patients with mild-to-moderate lung disease [6], and is the most important finding of this study.

On initial viewing there may appear to be a discrepancy in the data presented in tables 1 and 2 . Table 1 shows no difference in median pre- and postexercise $S \mathrm{a}_{1} \mathrm{O}_{2}$ between the two tests, but does show a lower first quartile $\mathrm{Sa}_{\mathrm{a}} \mathrm{O}_{2}$ poststep test compared with the first quartile $S \mathrm{a}, \mathrm{O}_{2}$ obtained postwalk test. When the desaturation recorded during each test is examined, there is a clear difference between the two tests (table 2, figs. 2 and 4). This apparent discrepancy is seen because some patients had a similar degree of desaturation with both tests, whilst some had a markedly greater desaturation with the step test.

One difficulty when conducting a study that compares two exercise tests, is the effect of fatigue upon the results of the second test. The present study followed a previous protocol [6] of waiting for $30 \mathrm{~min}$ after $\mathrm{Sa}_{\mathrm{a}} \mathrm{O}_{2}$ and $\mathrm{HR}$ had returned to baseline before commencing the second test. As these parameters may not measure fatigue or tendency to fatigue, the order of testing was alternated, and it was found that the order of testing had no effect upon results.

Measurement of exercise tolerance is considered an essential component of lung transplantation assessment, with reduced exercise tolerance considered a poor prognostic indicator. However, the interpretation of exercise test results is based upon limited data. Nixon et al. [9] reported an 8-yr follow-up of 107 patients with CF (mean age 17 yrs, range 7-35 yrs, mean FEV1 59\%, range 24-95\%) who had initially undergone maximal exercise testing on a cycle ergometer in the 1970s. They found that aerobic fitness (as measured by maximal oxygen uptake $\left.\left(V_{\mathrm{O}_{2}}, \max \right)\right)$ was the best predictor of survival over the study period. A similar study reported by MOORCRAFT et al. [10] in 1997 followed 92 adult patients over a 5-yr period and found that although $V \mathrm{O}_{2}$, max was a predictor of survival, the FEV1 was a better predictor. However, 
the form of exercise testing employed in these studies is expensive, time consuming, and requires a specialized laboratory. Few transplant centres assess exercise tolerance of lung transplant candidates in this way; the majority of centres use a submaximal test, most commonly the 6-min walk test. The distance walked during self-paced walk tests has been shown to correlate with resting pulmonary function and with aerobic fitness in both adults and children [2, 11, 12]. Furthermore, the minimum $\mathrm{Sa}_{\mathrm{a}} \mathrm{O}_{2}$ recorded during a walk test has been shown to correlate with the minimum $\mathrm{Sa}_{\mathrm{a}} \mathrm{O}_{2}$ recorded during progressive maximal exercise testing on a cycle ergometer [3]. However, there are limited data on the value of the walk test in predicting prognosis in pulmonary disease, with just four published survival studies $[4,5,13,14]$. Three of these studies were performed in adult subjects, one in subjects undergoing lung transplantation assessment [4], and two in subjects undergoing pulmonary rehabilitation. All three studies found timed (either 6-min or 12-min) walking distance to be a valuable predictor of survival. None of the studies evaluated minimum $\mathrm{Sa}_{\mathrm{a}} \mathrm{O}_{2}$ as a predictor of survival. The one paediatric study analysed survival of 181 children with CF referred to Great Ormond Street Hospital for Children for lung transplantation assessment between 1989 and 1999 [5]. This study suggested that minimum $\mathrm{Sa}_{\mathrm{a}} \mathrm{O}_{2}$ during a walk test is a better predictor of prognosis than distance covered.

Neither the step test nor the self-paced walk test is a true maximal exercise test. In the walk test, subjects are allowed to choose their own pace. In the step test the intensity and duration of the exercise is predetermined. The previous study suggested that the 3-min step test was harder exercise than the 6-min walk test, but also did not demonstrate any difference in desaturation between the two tests [6]. In the present study it has been shown that some children with more advanced $\mathrm{CF}$ lung disease desaturate dramatically during the 3-min step test, but not during the 6-min walk. This may be a consequence of lower resting arterial oxygen tension $\left(\mathrm{Pa}_{\mathrm{a}} \mathrm{O}_{2}\right)$ in these children. As the relationship between $\mathrm{Pa}, \mathrm{O}_{2}$ and $\mathrm{Sa}, \mathrm{O}_{2}$ is not linear, a small fall in $P \mathrm{a}, \mathrm{O}_{2}$ in a child with normal resting $P$ a, $\mathrm{O}_{2}$ (e.g. a fall from $12-11 \mathrm{kPa}$ ) will result in little desaturation. However, a small fall in $\mathrm{Pa}, \mathrm{O}_{2}$ in a child with mild hypoxia (e.g. a fall from $8-7 \mathrm{kPa}$ ) will produce a much greater desaturation. Thus the dramatic desaturation seen in some children undertaking the 3-min step test may represent greater oxygen consumption in a child who already has mild hypoxia.

This has implications for lung transplantation assessment. There is little doubt that resting $\mathrm{Pa}, \mathrm{O}_{2}$ and resting arterial carbon dioxide tension $\left(P \mathrm{a}, \mathrm{CO}_{2}\right)$ are of value in predicting prognosis of patients with $\mathrm{CF}[15,16]$. However, arterial blood sampling can be painful and technically difficult, so many transplant centres do not include this investigation as part of their paediatric assessment protocol [17]. None of the patients included in this study underwent arterial blood gas analysis. If the 3 -min step test is able to discriminate between children with normal resting $P \mathrm{a}, \mathrm{O}_{2}$ and good exercise tolerance, and children with lower resting $P \mathrm{a}, \mathrm{O}_{2}$ and poorer exercise tolerance, it may prove to be a valuable prognostic indicator in children being considered for lung transplantation. Longitudinal studies to evaluate this are underway.

In conclusion, the 3-min step test is easy to perform and is well tolerated even in children with moderate to severe cystic fibrosis lung disease. Furthermore, it produces a greater rise in heart rate and a greater fall in arterial oxygen saturation, particularly in those patients prone to desaturate during exercise, than the 6-min walk test. The 3-min step test may be of value when assessing a child's suitability for lung transplantation.

Acknowledgements. The authors would like to thank the children who gave their time to participate in this trial as well as J. Rae and all the staff of the Great Ormond Street Cardiothoracic Transplant Unit for their assistance.

\section{References}

1. Butland RJA, Pang J, Gross ER, Woodcock AA, Geddes DM. Two-, six-, and 12-minute walking tests in respiratory disease. $B M J 1982 ; 284$ : 1607-1608.

2. Gulmans V, van Veldhoven N, de Meer K, Helders P. The six-minute walking test in children with cystic fibrosis: reliability and validity. Pediatr Pulmonol 1996; 22: 85-89.

3. Nixon P, Joswaik M, Frickler F. A six-minute walk test for assessing exercise tolerance in severely ill children. J Pediatr 1996; 129: 362-366.

4. Kadikar A, Maurer J, Kesten S. The six-minute walk test: a guide to assessment for lung transplantation. J Heart Lung Transplant 1997; 16: 313-319.

5. Aurora P, Wade A, Whitmore P, Whitehead B. A model for predicting survival of children with cystic fibrosis. Eur Respir J 2000; 16: 1056-1060.

6. Balfour-Lynn IM, Prasad SA, Laverty A, Whitehead BF, Dinwiddie R. A step in the right direction: assessing exercise tolerance in cystic fibrosis. Pediatr Pulmonol 1998; 25: 278-284.

7. Rosenthal $\mathrm{M}$, Bain $\mathrm{SH}$, Cramer $\mathrm{D}$, et al. Lung function in white children aged 4 to 19 years: I Spirometry. Thorax 1993; 48: 794-802.

8. Bland JM, Altman DG. Statistical methods for assessing agreement between two methods of clinical measurement. Lancet 1986; 1: 307-310.

9. Nixon PA, Orenstein DM, Kelsey SF, Doershuk CF. The prognostic value of exercise testing in patients with cystic fibrosis. N Eng J Med 1992; 327: 17851788.

10. Moorcraft AJ, Dodd ME, Webb AK. Exercise testing and prognosis in adult cystic fibrosis. Thorax 1997; 52: 291-293.

11. Miyamoto $\mathrm{S}$, Nagaya $\mathrm{N}$, Satoh $\mathrm{T}$, et al. Clinical correlates and prognostic significance of six-minute walk test in patients with primary pulmonary hypertension. Comparison with cardio-pulmonary exercise testing. Am J Respir Crit Care Med 2000; 161: 487492.

12. Cahalin L, Paggagianopoulos P, Prevost S, Wain J, Ginns L. The relationship of the 6 minute walk test to maximal oxygen consumption in transplant 
candidates with end stage lung disease. Chest 1995; 108: 452-459.

13. Gerardi DA, Lovett L, Benoit-Connors ML, Reardon $\mathrm{JZ}$, ZuWallack RL. Variables related to increased mortality following out-patient pulmonary rehabilitation. Eur Respir J 1996; 9: 431-435.

14. Bowen JB, Votto JJ, Thrall RS, et al. Functional status and survival following pulmonary rehabilitation. Chest 2000; 118: 697-703.

15. Kerem E, Reisman J, Corey M, Canny GJ, Levison H.
Prediction of mortality in patients with cystic fibrosis. $N$ Engl J Med 1992; 326: 1187-1191.

16. Venuta F, Reudina EA, Rocca GD, et al. Pulmonary hemodynamics contribute to indicate priority for lung transplantation in patients with cystic fibrosis. J Thorac Cardiovasc Surg 2000; 119: 682689.

17. Whitehead B, Helms P, Goodwin M, et al. Heart-lung transplantation for cystic fibrosis. I: Assessment. Arch Dis Child 1991; 66: 1018-1021. 